\title{
A Novel Approach to Implement Self-Controlled Air Pollution Detection in Vehicles using Smoke Sensor
}

\author{
V V R Kishore Ch, Suman M \\ II Mtech Student,Assistant Professor \\ Department of electronics and communication engineering,
}

Vignan's Lara Institute of Technology and Science, Vadlamudi, Guntur district, Andhrapradesh, India

\begin{abstract}
--- vehicles became important in human life. This air pollution mainly caused by vehicles and industries. This paper mainly concentrated on controlling the air pollution from vehicles by using semi-conductor gas sensor for detecting the emission level from vehicles. If the vehicle do not get service regularly, then pollution level higher than standard emission level. In this paper, smoke sensor has been used to detect carbon monoxide from vehicles. Smoke sensor senses the pollution level from vehicles. If pollution level is recorded beyond the standard values from government, then microcontroller alerts the buzzer and displays pollution level on LCD. Microcontroller also sends pollution level to service centre through text message by GSM module. At the same time, activate the timer that indicates vehicle will be stopped after some time. During this time, GPS finds the location of vehicle in terms of latitude and longitude values and displays on LCD. GSM send GPS values to service centre through text message. When timer expires, vehicle will be stopped due to the fuel supply to engine get stop by relay circuit is controlled by microcontroller. Based on GPS values, service centre can trace and service the vehicle. The proposed system must be registered with service centre by sending text message. This paper will benefit to the society and help in controlling the air pollution.
\end{abstract}

Keywords- Air Pollution, Sensors, Standard Level, GPS, GSM, LPC2148 Microcontroller.

\section{INTRODUCTION}

In these days, air pollution is a major problem has been faced by mankind. The ozone layer got hole due to the greenhouse gases. These greenhouse gases released from industries and vehicles. Vehicles mainly release the carbon monoxide gas. This gas can have serious impact on human lungs and respiratory system. This gas can be easily detected by smoke sensors.

The main reason crossed the standard emission level crossed by vehicles due to the incomplete combustion of fuel supplied to engine. This kind of problems can occur due to the vehicles do not get service well. In this paper, mainly focus on controlling the air pollution from vehicles. GPS is mainly used to find location of vehicle. GSM is mainly used send messages to service centre.

\section{LITERATURE SURVEY}

The government made several regulations to control the pollution levels from vehicles. The Central Pollution Control Board under the Ministry of Environment \& Forests set standards and timeline for implementation to control emission level. The duty of this board is air quality monitoring. It runs the National Air Monitoring Programme (NAMP). The NAMP main objective is to determine the status of quality of air in environment and to control the pollution from industries and other sources to meet air quality standards.

The government of India introduced the Bharat Stage Emission Standards to control air pollution from vehicles. Several emission norms were come to control the emission levels from vehicles since two decades. First emission norms initiated for diesel and petrol engine vehicles. Later, European standards or European norms have been initiated in India in 2000. The vehicle manufacture companies started designing the new vehicles based on emission norm and regulations. Bharat stage IV norms have come in to force in place of 
Bharat stage III. In 2014, combination of Euro 3 and Euro 4 based norms will be applicable. These emission standards and emission norms are mainly for controlling the emission level from vehicles.

\section{PROPOSED SYSTEM}

\section{A. Self-Controlled Embedded System}

Microcontroller plays a vital role in this embedded system. The remaining modules are GPS, GSM, LCD, buzzer and relay are controlled by microcontroller. Microcontroller takes input from smoke sensor output. Based on smoke sensor output, microcontroller controls the remaining modules.

Based on programming the EEPROM of microcontroller, automatically microcontroller controls all the modules without any manual instructions.

\section{B. Self Checking the Emission Levels}

MQ-2 sensor is used to detect pollution levels from vehicles. If the pollution level of vehicle crosses the standard emission level, then vehicle will be stopped by microcontroller automatically.

\section{Smoke Sensor (MQ-2)}

Mq-2 sensor is also known as $\mathrm{CO}$ gas sensor. This sensor is made up of stannic oxide. In this paper, sensor is mainly used to detect carbon monoxide (CO) concentrations in air.

Whenever the CO concentration increases or exists in air, then sensor conductivity is high. We use simple circuit to convert the change of conductivity to correspond output signal of gas concentration. This sensor can also detect the combustible gas or flammable gas such as, methane, hydrogen and LPG.

The advantages are Long life and low cost. Good sensitivity to $\mathrm{CO}$ and combustible gases. It can detect combustible and smoke gases concentration from $300-10000 \mathrm{ppm}$ in air. This sensor can be fixed at emission outlets of vehicle.

\section{Microcontroller}

LPC2148 is the ARM 7TDMI based 32 bit microcontroller which has the maximum number of pins used to programming IO, Where the ports are mapped to virtual port. It has two 32-bit timers/external event counters (four captures and four compare channel each).

The microcontroller is used to perform four functions. First one is, compare emission values with standard values prescribed by government. Second one is, activates the timer and alerts the buzzer to indicate vehicle will be stopped after sometime due to the violation of standard emission values. Third one is, microcontroller activate the GPS to find location of vehicle and display in terms of latitude and longitude. Fourth one is, GSM module is activated by microcontroller to send GPS values to service centre through text message. The microcontroller performs functions according to the software programmed in EEPROM of microcontroller.

\section{E. Block Diagram}

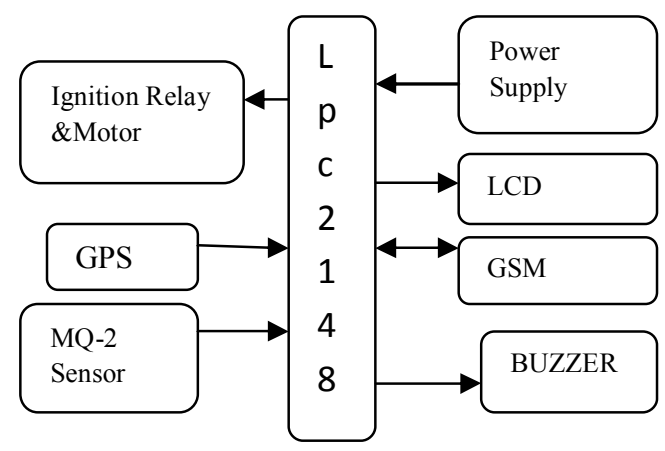

Fig. 1 Block Diagram

\section{F. Proposed Algorithm}

- The proposed system detects the emission level from vehicle by using mq-2 sensor.

- If the vehicle crosses the standard level or threshold level, immediately the system will alert the driver to service the vehicle through buzzer and also displays pollution level on LCD as well as send to service centre through text message. It also indicates after some time the vehicle will get stop.

- During this time, GPS find the location of vehicle in terms of latitude 
and longitude and also displays on LCD.

- The GPS values send to service centre by GSM module.

- When the timer expires, the vehicle will be stopped.

\section{G. Fuel Injector}

Whenever the level of pollution crosses the standard level or threshold level which have been prescribed by government, then fuel injector break the fuel supplied to engine using relay circuit.

The fuel injector takes the input from microcontroller and gives its output to motor. The fuel pump can be on or off by using relay circuit. If there is no pollution from vehicle, then ignition switch is in on state .so, vehicle is keep moving. If the pollution level crosses standard level, then ignition switch comes in to off state by using relay to control fuel pump. So, vehicle will be stopped.

\section{H. Global Positioning Systems (GPS)}

Whenever the pollution level reaches to maximum limit, a trigger pulse is given to GPS by microcontroller. The GPS is programmed when GPS receives a trigger pulse, it starts showing the location of vehicle continuously until the vehicle will be stopped.

\section{Global System for Mobile Communications (GSM)}

Whenever the GPS starts showing the location, then GSM module automatically sends a GPS values through text message to service centre by microcontroller. Max 232 provides serial communication between GSM module and microcontroller.

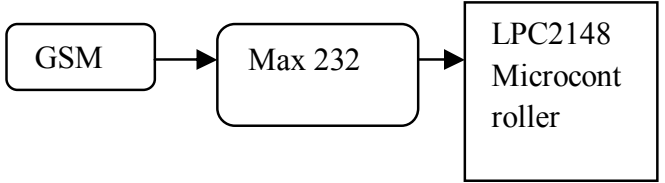

Fig. 2 Serial Communication among GSM and Microcontroller

At the time of registration with service centre number, first we have to send text message to GSM module of proposed system for storing service centre number in microcontroller. After that, the service centre received message "Number Registered" from the GSM module of proposed system. In this paper, GSM module plays a crucial role.
J. System Design

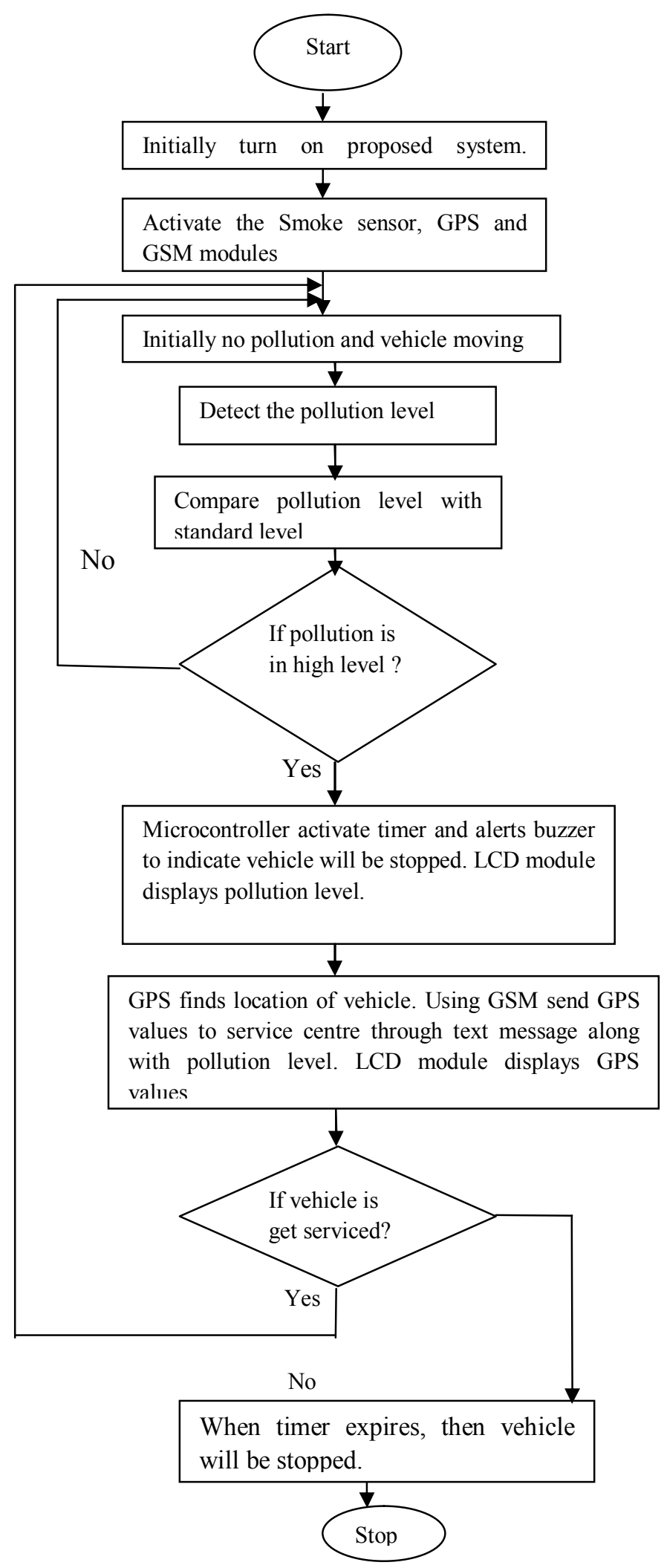

Fig. 3 Flowchart to Proposed System 


\section{RESULTS}

A. Hardware Setup of Proposed System

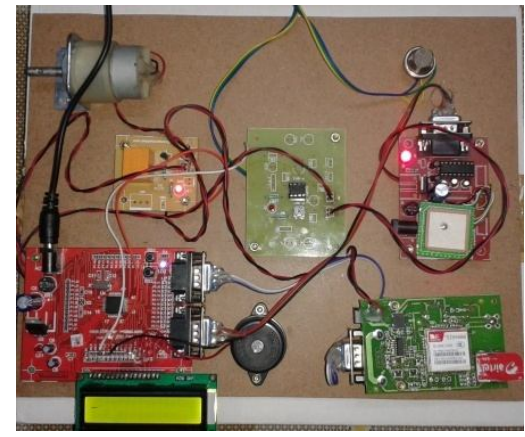

Fig. 4 Hardware Setup

- Initially proposed system at idle state.

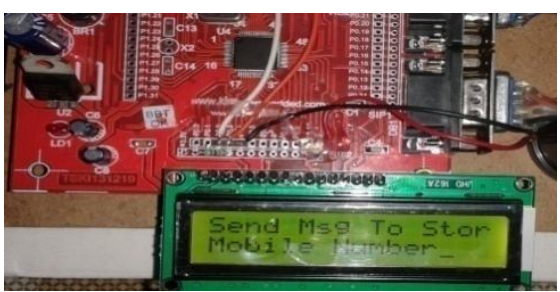

Fig. 5 Register with Service Centre

- This message indicates proposed system must be registered with service centre, before this system insert in to vehicles.

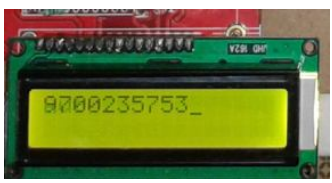

Fig. 6 Service Centre Number

- After registered with service centre, the service centre number is displayed.

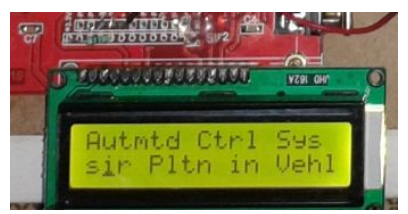

Fig. 7 Proposed System is working

- And also display the message that the proposed system is working (automated control system for air pollution detection is activated).

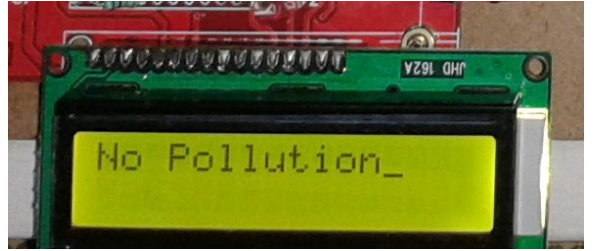

Fig. 8 No Pollution

- Initially there is no pollution. The vehicle is keep moving.

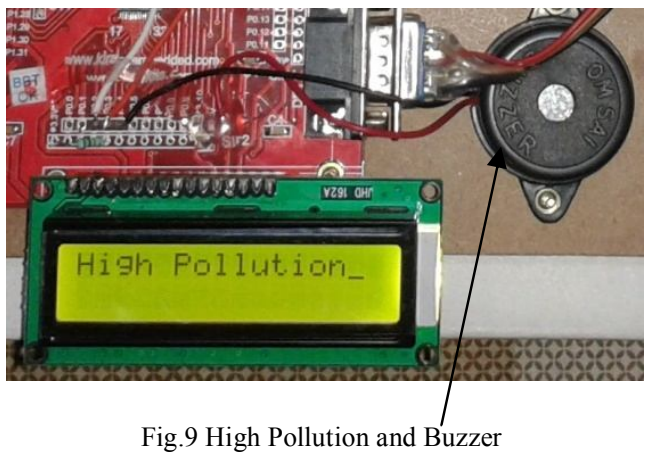

- Whenever pollution emission level beyond threshold level, there will be a buzzer alert to indicate breach level in vehicle and also after some time vehicle will stop. A cushion period is given to driver to park his or her vehicle.

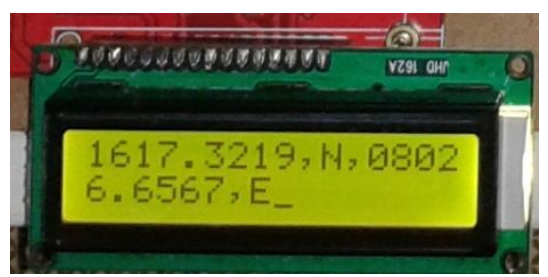

Fig. 10 GPS Values

- During this period, GPS automatically find the location of vehicle and display it through the latitude and longitude values by microcontroller. GSM module send both latitude and longitude values through text message to service centre.

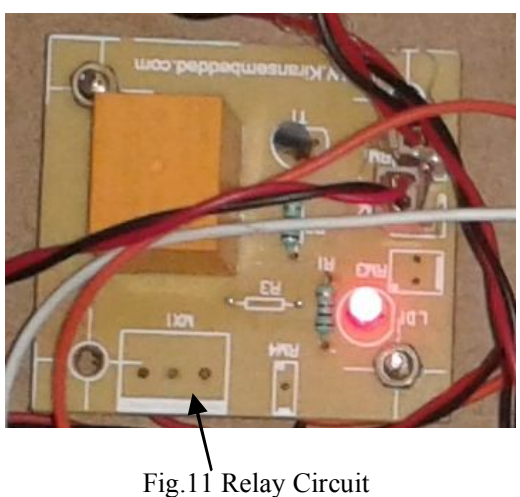


- After cushion period expires, the fuel is supplied to engine will be cut-off by using above relay circuit which can act as switch.

In this proposed system, mq-2 gas sensor has been used to detect $\mathrm{CO}$ concentration in air, whenever $\mathrm{CO}$ concentration is raised. It can also detect flammable or combustible gas concentrations, when it is present in air.

\section{CONCLUSION}

This paper mainly focuses on three concepts. The first concept is, detecting pollution level from vehicles and represent to driver of vehicle. The second concept is, avoiding the inconvenience to driver of the vehicle by sending text message to service centre using GSM module. The proposed system can control the pollution. The third concept is, it can be easily deployed in vehicles. In this project, mq-2 gas sensor has been used to detect $\mathrm{CO}$ concentrations in air. It can also detect combustible gas which can lead to heavy explosions. This kind of sensors can also more useful in industries. The same concept can also be extended to industries.

\section{REFERENCES}

[1] http://en.wikipedia.org/wiki/Bharat Stage emission standards

[2] http://www.cpcb.nic.in/Introduction.php

[3] http://en.wikipedia.org/wiki/Emission_standard

[4] Siva Shankar Chandrasekaran, Sudharshan Muthukumar and Sabeshkumar Rajendran, "Automated Control System for Air Pollution Detection in Vehicles" $20134^{\text {th }}$ International Conference on Intelligent Systems, Modelling And Simulation.

[5] George F. Fine, Leon M. Cavanagh, Ayo Afonja and Russell Binions, "Metal Oxide Semi-Conductor Gas Sensors in Enviromental Monitoring”, Sensors 2010, 10, 5469-5502: doi:10.3390/s100605469.

[6] K. Galatsis, W. Wlodarsla, K.Kalantar-Zedeh and A. Trinchi, "Investigation of gas sensors for vehicle cabin air quality monitoring," vol.42,pp. 167-175, 2002

[7] "Trade of Motor Mechanic"; Module 5; Unit 2 Electronic Fuel Injection; Phase 2 by FAS Learning Innovation Unit with Martin Mcmahon \& CDX Global; Curriculum Revision 2.2 16-01-07.

[8] LIU Zhen_ya, Wang Zhen-dong, CHEN Rong, " Intelligent Residential Security Alarm and Remote Control System Based On Single Chip Computer," vol. 42, pp. 143-166, 2008.

[9] P.Vijnatha Raju, R.V.R.S.Aravind, B.Sangeeth Kumar, "Pollution Monitoring System Using Wireless Sensor Network In Visakhapatnam", IJETT, Volume4, Issue4, April-2013.

[10] G.Anuradha, "Self Automated Tool in Vehicular System That Identifies the Air Pollution and the Future of E-Governs", IJIES, Volume, Iissue12, November 2013

[11] Anita Kulkarni, Ravi Teja, "Automated System for Air Pollution Detection and Control in Vehicles", IJAREEIE, vol 3, issue 9, September 2014.

[12] Amarakanth, N.V.Uma Reddy, "Engine Self-Test With Air Pollution Detection and Remote
Information System", IJRET, Vol 3, Special Issue 3 May-2014.

[13] "Smart Sensor Networks: Technologies and Application for Green Growth", OECD, 2009.

[14] www.pololu.com/file/0J309/MQ2.pdf

[15] http://en.wikipedia.org/wiki/Global Positioning Syst em

[16] http://en.wikipedia.org/wiki/GSM

[17] http://www.askindiatech.com/Dpdf/LPC2148\%20Fe ature $\% 20$ List,pdf 